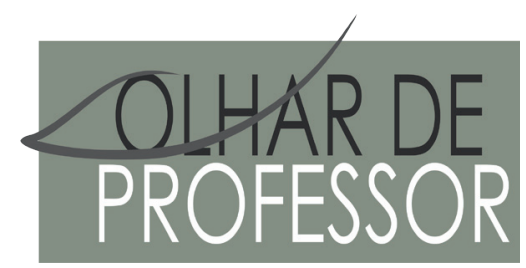

DOI: 10.5212/OLHARPROFR.v.23.2020.16011.209209226562.0614

\title{
REFLEXÕES PEDAGÓGICAS EM TEMPOS DE PANDEMIA: ANÁLISE DO PARECER 05/2020
}

\author{
PEDAGOGICAL REFLECTIONS IN PANDEMIC TIMES: ANALYSIS OF THE OPINION 05/2020 CNATIONAL \\ COUNCIL ON EDUCATION]
}

REFLEXIONES PEDAGóGICAS EN TIEMPOS PANDÉMIICOS: ANÁLISIS DEL DICTAMEN CNE.05/20२०

\author{
ALINE DAIANE NUNES MASCARENHAS* \\ AMÉLIA DO ROSÁRIO SANTORO FRANCO**
}

\begin{abstract}
Resumo: O contexto da pandemia no cenário atual e a recente recomendação do Parecer CNE 05/2020 realiza um convite à Pedagogia enquanto campo de conhecimento dos fenômenos educativos a uma importante reflexão: que intencionalidades pedagógicas estão presentes no parecer CNE 05/2020 ao regulamentar a atividade não presencial em tempos de pandemia? Este estudo realiza uma análise do cenário atual, a partir de uma investigação documental do Parecer CNE 05/2020 aprovado como uma diretriz legal que reorganiza o calendário escolar mediante o ensino remoto com atividades não presenciais, em razão da Pandemia da COVID-19. Após análise crítico-interpretativa, constata-se que o parecer está alicerçado num princípio educativo formal-tecnicista de cumprimento das 800 horas curriculares; desconsidera as desigualdades sociais e tecnológicas presentes no território brasileiro, comete uma injustiça cognitiva, constituindo-se como uma proposta elitista, discriminatória e perversa aos alunos da escola pública.
\end{abstract}

Palavras-chave: Prática pedagógica. Ensino remoto. Parecer 05/2020.

Abstract: The context of the pandemic in the current scenario and the most recent recommendation from CNE 05/2020 invites Pedagogy, while the field of knowledge of educational education phenomenon to reflect upon an importante consideration: which pedagogical intentionalities are present in the opinion of CNE 05 / 2020 when regulating the teching out-of-school in pandemic times? This study performs an analysis of the current scenario, based on a documentary investigation of Opinion CNE 05/2020, approved as a legal guideline that reorganizes the school calendar using remote teaching with non-face-to-face activities, due to the COVID-19 Pandemic. After the critical-interpretative analysis, it appears that the opinion is approved on a technical educational principle of compliance with 800 curricular hours; it disregards the social and technological inequalities present in the Brazilian territory, as a cognitive injustice, constituting itself as an elitist, discriminatory and perverse proposal for public school students.

Keywords: Pedagogical practice. Remote teaching. Opinion 05/2020.

Resumen: El contexto de la pandemia en el escenario actual y la reciente recomendación del Dictamen CNE 05/2020 invita a la Pedagogía como campo de conocimiento de fenómenos educativos a una reflexión importante: qué intenciones pedagógicas están presentes en el dictamen CNE 05/2020 al regular el actividad no presencial en tiempos de pandemia? Este estudio realiza un análisis del escenario actual, basado en una investigación documental del dictamen CNE 05/2020 aprobada como una guía legal que reorganiza el calendario escolar a través de la enseñanza remota con actividades no presenciales, debido a la pandemia COVID-19. Después de un análisis crítico-interpretativo, parece que la opinión se basa en un principio educativo formal-técnico de cumplimiento de

\footnotetext{
*Doutora em Educação pela UFBA. Docente Adjunta da Universidade do Estado da Bahia. E-mail: aline_mascarenhas@ hotmail.com

${ }^{* * *}$ Doutora em Educação pela Universidade de São Paulo. Docente da Universidade Católica de Santos. E-mail: ameliasantoro@uol.com.br
} 
800 horas curriculares; ignora las desigualdades sociales y tecnológicas presentes en el territorio brasileño, comete una injusticia cognitiva, constituyéndose en una propuesta elitista, discriminatoria y perversa para estudiantes de escuelas públicas.

Palabras clave: Práctica pedagógica. Enseñanza a distancia. Dictamen 05/2020.

\section{INTRODUÇÃO}

A pandemia que ora nos atinge impede encontros pedagógicos presenciais. Crianças e adolescentes não podem estar fisicamente presentes na escola, estão distantes de seus colegas e professores, dos sorrisos, dos abraços e dos afetos. Esta situação se apresenta desafiadora para educadores que sabem que a presença coletiva e múltipla produz condições insuperáveis para a socialização e fundamentação de processos de formação de sujeitos. O inevitável e necessário isolamento social impactou os sistemas de educação, em todo o mundo: em pouco mais de três semanas, cerca de 1,7 bilhão de alunos, de diferentes níveis e faixas etárias, pelo menos em 193 países, ficaram fora da escola em todo o mundo (UNESCO, 2020). No Brasil, as instituições escolares estão temporariamente fechadas, as aulas foram suspensas e o calendário letivo paralisado.

Esta situação coloca a urgente necessidade, no cenário da educação, de uma diretriz legal que oriente escolas, professores e famílias quanto ao reordenamento da continuidade da educação escolar. O momento é complexo, desafiador e angustiante, e, no contexto brasileiro, a situação se complica ainda mais em decorrência da aprovação da PEC 55/2016, ${ }^{1}$ que limita durante 20 anos os gastos com áreas prioritárias, a exemplo da saúde e educação, agravando ainda mais o cenário. Qual foi a normatização legal encontrada no Brasil para orientar escolas e professores frente a esta emergência pedagógica? Em 28 de abril de 2020, o Conselho Nacional de Educação, nesse cenário emergente, aprovou o Parecer 05/2020 (BRASIL, 2020), que versa sobre a reorganização do calendário escolar e da possibilidade de cômputo de atividades não presenciais para fins de cumprimento da carga horária mínima anual, em razão da pandemia da COVID-19.

Esse contexto adverso nos convida a uma reflexão no campo da educação e nos instiga a analisar a seguinte questão: que intencionalidades pedagógicas estão presentes no parecer CNE 05/2020 ao regulamentar a atividade não presencial em tempos de pandemia?

A discussão aqui é empreendida por se tratar de um tema recente, ainda com publicações quase inexistentes e terá a perspectiva de ensaio teórico-crítico, com base em pesquisa documental e bibliográfica e análise crítico-interpretativa dos dados.

\section{OENSINO REMOTO OU ENSINO ON-LINE}

O Parecer 05/2020 (BRASIL, 2020), que instrui sobre a reorganização do calendário escolar e sobre a possibilidade de cômputo de atividades pedagógicas não presenciais para fins de cumprimento da carga horária mínima anual, define as atividades não presenciais mediadas ou não pelas tecnologias da informação como um caminho favorável para o cumprimento do calendário escolar e durante o período de interrupção das aulas presenciais em instituições de ensino público e privado.

O parecer traz como uma das questões centrais o ensino remoto com atividades não presenciais, como forma de dar continuidade ao currículo escolar e na escolarização de conteúdos, sendo favorável à garantia das 800 horas no cumprimento do ano letivo escolar. O documento evoca de maneira arbitrária a continuidade do processo de aprendizagem dos sujeitos, mediante aulas não presenciais como forma de cumprimento do calendário escolar e a garantia das competências explicitadas na Base Nacional Comum Curricular - BNCC, sem aprofundar as especificidades e desigualdades presentes nas diversas regiões do

\footnotetext{
${ }^{1}$ Emenda Constitucional n. 95/2016, que estabeleceu um teto para as despesas primárias de recursos destinados às ações e serviços públicos durante um período de 20 anos.
} 
país, desconsiderando a função social da escola e, ainda, sem a problematização do processo de ensino e aprendizagem no contexto não presencial.

As atividades acadêmicas de modo remoto não significam a troca de modalidade de ensino presencial para a educação a distância, pois esse regime de atividade (atividade remota) é temporário e atende ao período de pandemia da COVID-19. A educação a distância e o ensino remoto resguardam diferenças metodológicas e operacionais no cumprimento das atividades: a) educação a distância possui aulas gravadas e ficam no sistema para que o discente estude em horário e local que quiser; material com conteúdos padronizados a todos os cursos; aulas regulamentadas pelo Decreto Federal n ${ }^{\circ} 5622$ de 19 dezembro de 2005, que regulamenta o art. 80 da Lei 9.394, de 20 de dezembro de 1996, que estabelece as diretrizes e bases da educação nacional e caracteriza a educação a distância como modalidade educacional; b) o ensino com aulas remotas ocorrem com professores online e em tempo real da aula presencial, com a suposta interação de alunos com ferramentas pedagógicas que podem ser utilizadas após as aulas remotas; material exclusivo feito por professores da disciplina; supõe, portanto, um tempo extra de professores para preparo, organização e acompanhamento dos alunos.

Ao simplesmente propor o ensino remoto, o referido parecer não demonstra preocupação com quem recebe a educação. Não organiza formas e meios de incluir a totalidade da população escolar com frágil acesso à tecnologia ${ }^{2}$. Enaltece apenas a possibilidade de cumprir dias letivos e disponibilização de informes de conteúdo, no pressuposto de que isso seja ensino.

A educação remota, assim preconizada, configura-se como a pior forma de educação bancária; não há compromisso com o Outro da educação. Não há possibilidade de adequação dos conteúdos curriculares às especificidades dos alunos. É um pacote de transmissão com a preocupação única de cumprir burocraticamente a exigência de dias letivos. Mais uma barbárie posta pela lógica tecnológica em detrimento à lógica humanista.

\section{ENSINAR APRENDER: UM CIRCUITODIALÉTICO}

O Brasil possui, segundo dados do Censo Escolar de 2019 (INEP, 2020), mais de 5 milhões de estudantes entre 4 e 5 anos de idade, cerca de 13.700 .000 estudantes entre 5 e 10 anos de idade e mais de 10 milhões na faixa entre 10 e 14 anos de idade. Portanto, há mais de 28 milhões de estudantes que, atualmente, diante da pandemia, estão ausentes de forma presencial da instituição escolar.

As atividades não presenciais, conforme o Parecer CNE 05/2020, são compreendidas como:

[...] aquelas a serem realizadas pela instituição de ensino com os estudantes quando não for possível a presença física destes no ambiente escolar. A realização de atividades pedagógicas não presenciais visa, em primeiro lugar, que se evite retrocesso de aprendizagem por parte dos estudantes e a perda do vínculo com a escola, o que pode levar à evasão e abandono (BRASIL, 2020).

Adentrando no sentido desta proposta, vamos analisar a questão: o que é aprendizagem? Por que e como ela retrocede e, o mais importante, que tipo de aprendizagem tem retrocessos? A situação é bastante complexa e por certo perpassa o sentido de aprender. Sabe-se, pelos estudos e pesquisas de teóricos cognitivos (AUSUBEL, 1976; PIAGET, 1978; VIGOTSKI, 1991), que a aprendizagem verdadeira cria novos sentidos e novas possibilidades para o aluno compreender e significar o mundo. O que é aprendido altera as estruturas cognitivas e permite que o sujeito crie e construa novas configurações mentais e afetivas.

Como já escreveu Franco (2015), as aprendizagens decorrem de sínteses interpretativas realizadas nas relações dialéticas do sujeito com seu meio. Não são imediatas, não são previsíveis, ocorrem por interpretação do sujeito, dos sentidos criados, das circunstâncias atuais e antigas, ou seja, não há correlação direta entre ensino e aprendizagem. Quase que se pode dizer que as aprendizagens ocorrem sempre para além ou para aquém do planejado; nos caminhos tortuosos, lentos e dinâmicos das trajetórias dos sujeitos.

\footnotetext{
${ }^{2}$ Reportagem veiculada pela Folha de São Paulo, em 14 de maio de 2020, afirma que menos da metade da rede estadual de ensino participa das aulas remotas pelo aplicativo on line de atividades remotas (PINHO, 2020).
} 
Assim, a verdadeira aprendizagem produz uma reconfiguração nos modos e meios de olhar, sentir e compreender o mundo. Só a aprendizagem de memorização, de repetição, de ausência de sentido produz retrocessos na própria uma aprendizagem. As aprendizagens são cumulativas e requerem um ensino problematizador, contextualizado e crítico. Talvez seja esse o cerne da questão: como se pode, em situações de enormes desigualdades sociais e de frágil acesso aos meios digitais, criar um ambiente para envolver o aluno em processos de ensinar-aprender?

Ainda aprofundando a leitura: o abandono da escola se faz por múltiplos e complexos motivos. Como alerta Freire (2004a), ao realçar que não há evasão escolar e sim "expulsão escolar”, que se configura em uma injustiça e que precisa, do ponto de vista ético, causar indignação e atitude de mudar a cara da escola de autoritária e excludente para inclusiva e democrática.

A escola ainda cumpre a tarefa de se tornar um ambiente social de trocas culturais, de vivências coletivas, de espaço de construção de afetividades, de pesquisa e criatividade. O Parecer do CNE 05/2020 não dimensiona, ao longo do texto, nenhuma reflexão sobre o importante papel que cumpre a escola na sociedade, colocando a educação apenas sobre o prisma do conteudismo e do cumprimento burocrático do ano letivo. No entanto, o que está em jogo é o papel da escola e do ensino, quer presencialmente e quer on-line, numa sociedade de enormes desigualdades sociais. A desconsideração dessa realidade social de desigualdade endêmica é geradora de não aprendizagens.

É imperioso reconhecer a escola como um espaço que vem sendo desprezado, em sua função crítico-humanizadora. A pandemia trouxe à tona algo que estava sendo invisibilizado: a forma inadequada e desprezível que a escola, especialmente a pública, tem sido tratada em detrimento de sua especificidade em prol do mercado da educação.

A situação atual deixa claro que a educação mediada pela família, utilizando a casa como espaço físico, não substituirá o professor, nem o espaço escolar, que tem o papel crucial em promover não apenas o processo de aprendizagem dos sujeitos, mas se constitui como um espaço de diversidade cultural, combate ao machismo e aos diferentes preconceitos, emancipação social, lugar de reflexão dos problemas sociais e desenvolvimento pleno do sujeito.

A Constituição Federal de 1988 (BRASIL, 1988) defende a escola como o tripé da formação para a cidadania, desenvolvimento pleno da pessoa e o mundo do trabalho, assim, a instituição familiar na vida do sujeito cumpre outros papéis importantes, mas que não devem ser confundidos com os papéis da escola.

A defesa da finalidade do processo educativo no Parecer 05/2020 (BRASIL, 2020) como sendo o atendimento dos direitos e objetivos de aprendizagem previstos para cada etapa educacional, por meio das competências previstas na BNCC, escancara a lógica tecnicista que segue o atual governo, denuncia a preocupação exclusiva na prescrição curricular, deixando de lado a educação em sua dimensão social, histórica e humanizadora.

O parecer do CNE 05/2020 define ainda, as “atividades pedagógicas não presenciais” como práticas pedagógicas mediadas ou não por tecnologias digitais de informação e comunicação, a serem utilizadas para a reorganização dos calendários escolares, durante o período de isolamento social, para cumprimento das horas letivas anuais (BRASIL, 2020). Assim, orienta, sobretudo na educação infantil e ensino fundamental, que as atividades sejam feitas com a mediação de pais, mães ou responsáveis, devendo a escola enviar guias de orientação às famílias, orientando o acompanhamento dos estudantes. O documento explicita a realização de prática pedagógica perante a mediação de familiares. Qual o conceito de prática pedagógica adotada pelo parecer?

Tomando como referência o conceito de Franco (2016), as práticas pedagógicas são práticas que se realizam para organizar/potencializar/interpretar as intencionalidades de um projeto educativo, tendo como referência uma perspectiva crítica e não normativa. Essa definição é muito importante por nos convidar a algumas reflexões: a) será que a atividade não presencial em tempos de pandemia será mediatizada a partir de uma prática pedagógica (sentido real) no contexto das famílias brasileiras? b) os responsáveis pela mediação dessas atividades conseguem acompanhar os códigos e linguagens da escola para pautar-se em uma prática pedagógica que não seja normativa?

De acordo com o documento oficial, as atividades não presenciais podem acontecer por meios digitais (videoaulas, conteúdos organizados em plataformas virtuais de ensino e aprendizagem, redes sociais, 
correio eletrônico, entre outros); por meio de programas de televisão ou rádio; pela adoção de material didático impresso com orientações pedagógicas distribuído aos alunos e seus pais ou responsáveis; e pela orientação de leituras, projetos, pesquisas, atividades e exercícios indicados nos materiais didáticos.

Esse parecer, escrito de forma tão fantasiosa, ignora as impossibilidades da situação real de nossas escolas; desconhece e afronta a garantia de acesso e permanência de milhões de sujeitos que, em diferentes regiões do país, não têm garantido o acesso à internet, agrava a vulnerabilidade das populações que vivem marginalizadas e discute o processo educativo apenas pelo viés da escolarização, das competências da BNCC, precarizando o trabalho docente e pormenorizando a educação inclusiva.

A atividade não presencial por mídia digital requer uma estrutura bem mais complexa que a presencial, pois necessita que cada família disponha de computador com acesso à internet ou um celular com disponibilidade de dados móveis para acessar a plataforma, link, vídeo aula e ou orientações escolares. No Brasil, existem desigualdades digitais retratadas pela diversidade de lugares que ainda nem possuem sinal digital, a exemplo dos estados como Amazonas e Pará, em que os alunos precisam se deslocar de barco para as escolas e possuem acesso reduzido a sinais digitais.

Embora eleja a utilização de material impresso como outra possibilidade, além do meio digital, não leva em conta o contexto de pandemia e a necessária quarentena, que inviabiliza a ida das famílias à instituição escolar para adquirirem o material didático, sem falar no risco de aglomeração, e, portanto, o perigo de contaminação. Será que, subjetivamente, os pareceristas acreditam que milhões de lares brasileiros em que residem nossos alunos possuem impressora e internet para acessar atividades? De uma forma ou de outra, essas duas possibilidades se tornam improváveis na garantia de acesso e sucesso a todos os sujeitos da escola pública.

Mais grave ainda é desconhecer a natureza de processos pedagógicos de ensinar e aprender e desconsiderar as especificidades de cada faixa etária. Uma criança pequena precisa de situações vivenciáveis através da pesquisa, da criatividade, da curiosidade epistemológica.

\section{CONSIDERAÇ̃̃ES}

O Parecer 05/2015 mostra inúmeras fragilidades e não se concretizará na prática, pois se revela como uma proposta elitista, uma vez que só famílias com acesso aos meios digitais conseguem dar conta dessa emergência educacional, sendo negligente quanto aos processos formativos.

No contexto operacional, a atividade não presencial pelas mídias digitais invisibiliza a realidade das famílias de baixa renda, as quais, em sua maioria, possuem reduzido acesso a dados móveis e números insuficientes de aparelhos, protagonizando um empecilho na continuidade das aulas, que por vezes ocorrem concomitantemente com outras demandas trabalhistas. Não basta a continuidade do processo educativo mediado pela teia curricular no sentido da escolarização, mediante a transposição de atividades planejadas em plataformas, atividades impressas ou meios de comunicação, com um caráter de ensino instrucionista e passivo, com a padronização de currículo, sem considerar dificuldades próprias dos sujeitos nesse itinerário da aprendizagem, relegando o papel crucial do professor nesse processo. No mais, corremos o risco de vivenciar a fase do improviso na educação.

A educação como um direito humano, conforme preconiza a Constituição de 1988, é um "direito de todos” (BRASIL, 1988), portanto, não pode excluir e gerar mais desigualdades, reduzindo o processo educativo ao cumprimento de conteúdo com prescrições curriculares. O processo de ensino e aprendizagem deve ser centrado no sujeito e não na submissão de uma lógica perversa de cumprimento da carga horária de 800 horas. O presente parecer é um documento discriminatório e perverso aos alunos da escola pública.

\section{REFERÊNCIAS}

AUSUBEL, D. P. Psicología educativa. Un punto de vista cognoscitivo. México: Ed. Trillas, 1976. 
BRASIL. Constituição da República Federativa do Brasil de 1988. Brasília, DF: Presidência da República, 1998. Disponível em: http://www.planalto.gov.br/ccivil_03/Constituicao/. Acesso em: 10 jun.2020.

BRASIL. Decreto ${ }^{0}$ 5.622, de 19 de dezembro de 2005. Regulamenta o art. 80 da Lei no 9.394, de 20 de dezembro de 1996, que estabelece as diretrizes e bases da educação nacional. Diário Oficial da União de 20/12/2005.

BRASIL. Emenda Constitucional $\mathbf{n}^{\circ}$ 95, de 15 de dezembro de 2016. Altera o Ato das Disposições Constitucionais Transitórias para instituir o Novo Regime Fiscal e dá outras providências

BRASIL. Ministério da Educação e Cultura. Conselho Nacional de Educação. Parecer 05/2020. Reorganização do Calendário Escolar e da possibilidade de cômputo de atividades não presenciais para fins de cumprimento da carga horária mínima anual, em razão da Pandemia da COVID-19. Disponível em: http://portal.mec.gov.br/conselho-nacional-de-educacao/atos-normativos--sumulas-pareceres-eresolucoes/33371-cne-conselho-nacional-de- educacao/85201-parecer-cp-2020. Acesso em: 07 maio 2020.

FRANCO, M. A. S. Práticas pedagógicas de ensinar-aprender: por entre resistências e resignações. Educ. Pesquisa, São Paulo, v. 41, n. 3, p. 601-614, jul./set. 2015.

FRANCO, M.A.S. Prática pedagógica e docência: um olhar a partir da epistemologia do conceito. Rev. bras. Estud. pedagog., Brasília, v. 97, n. 247, p. 534-551, set./dez. 2016.

FREIRE, P. Entrevista com Paulo Freire: a educação neste fim de século. In: GADOTTI, M. (org.). Convite à leitura de Paulo Freire. São Paulo: Scipione. 2004a.

INEP. Instituto Nacional de Estudos e Pesquisas Educacionais Anísio Teixeira. Censo Escolar 2019. Disponível em: http://portal.inep.gov.br/. Acesso em: 10 jul. 2020.

PIAGET, J. A. Equilibração das estruturas cognitivas: problema central do desenvolvimento. Trad. Álvaro Cabral. Rio de Janeiro: Zahar, 1978.

PINHO, A. Menos de metade dos alunos da rede estadual de SP acessa ensino online na quarentena. Folha de S. Paulo, 14 de maio de 2020. Disponível em: https://www1.folha.uol.com.br/educacao/2020/05/ menos-de-metade-dos-alunos-da-rede-estadual-de-sp-acessa-ensino-online-na-quarentena.shtml. Acesso em: 10 ago. 2020.

UNESCO. A Comissão Futuros da Educação da Unesco apela ao planejamento antecipado contra o aumento das desigualdades após a COVID-19. Paris: Unesco, 16 abr. 2020. Disponível em: https:// pt.unesco.org/news/comissao-futuros-da-educacao-da-unesco-apela-ao-planejamentoantecipado-0-aumento-das. Acesso em: 25 de abril de 2020.

VIGOTSKI, L. S. Aprendizagem e desenvolvimento intelectual na idade escolar. In: VIGOTSKI, L. S. et al. (org.). Psicologia e Pedagogia I: bases psicológicas da aprendizagem e do desenvolvimento. 2. ed. Lisboa: Estampa, 1991. 